PERSPECTIVAS de las Ciencias Económicas y Jurídicas • Facultad de Ciencias Económicas y Jurídicas de la UNLPam. • Volumen 8 - № 2 - Año 2018

Álvarez Cuellar, Y. (2018). "LA EXTENSIÓN: UN LEGADO VIGENTE A 100 AÑOS DE LA REFORMA UNIVERSITARIA" Revista Perspectivas de las Ciencias Económicas y Jurídicas. Vol. 8, N² (juliodiciembre). Santa Rosa: FCEyJ (UNLPam); EdUNLPam; ISSN 2250-4087, e-ISSN 2445-8566 pp. 131-134. DOI http://dx.doi.org/10.19137/perspectivas-2018-v8n2a08.

Fecha de recepción: 29/09/2017 - Fecha de aprobación: 26/4/2018

\title{
LA EXTENSIÓN: UN LEGADO VIGENTE A 100 AÑOS DE LA REFORMA UNIVERSITARIA
}

Yasmin ÁLVAREZ CUELLAR

Corría el año 1918 y la Argentina vivía un clima de convulsión social pocas veces antes visto. Ya sea porque hacía apenas dos años había llegado al poder el primer presidente electo democráticamente por la voluntad popular, Hipólito Irigoyen, o porque el aluvión de inmigrantes que había arribado al país había traído consigo nuevos aires revolucionarios; la cuestión es que el país, estaba siendo testigo de profundos cambios y movilizaciones sociales que harían temblar las bases de la institución universitaria tal como era concebida hasta ese momento.

Fue en la ciudad de Córdoba, cuya universidad antecedía a la propia independencia argentina, donde un grupo de estudiantes universitarios liderados por Deodoro Roca, decidieron revelarse ante el modelo escolástico tradicional que sostenía una estructura de funcionamiento anacrónica y antidemocrática.

El programa de la Reforma Universitaria pudo vislumbrase por primera vez en el Congreso Nacional de Estudiantes Universitarios que congregó a representantes de las universidades argentinas. En el Congreso se sancionó un Proyecto de Ley Universitaria y un proyecto de bases estatutarias cuyo contenido reflejaba los principios sobre los cuáles debería basarse la Nueva Universidad (Carlos Tünnermann Bernheim; 2008). Ello dio origen a que se plasmaran una serie de postulados que versaban sobre contenidos de índole estrictamente académica, pero también relacionados con cuestiones sociales y políticas, que redefinirían la relación entre la universidad y la sociedad.

Considero conveniente resumir los principios sostenidos por la Reforma de la siguiente manera:

a) Principios relacionados con la organización y gobierno de la Universidad entre los cuáles se pueden mencionar: la autonomía universitaria, la autarquía financiera y el co-gobierno estudiantil.

b) Principios vinculados con la enseñanza y métodos docentes entre los cuáles encontramos: los concursos de oposición para la elección de profesores, la periodicidad de las cátedras, la docencia y asistencia libre, la reorganización académica, la modernización de los métodos de enseñanza, y la vinculación con el sistema educativo nacional.

${ }^{1}$ Abogada. UNLPam, FCEyJ, Santa Rosa, Argentina. yasmin-a@hotmail.com.ar 
c) Los postulados referentes a la proyección política y social de la Universidad que incluyen: la gratuidad de la enseñanza, la asistencia social a los estudiantes, la extensión universitaria y la unidad latinoamericana en la lucha contra las dictaduras y el imperialismo.

Es en el último apartado donde se encuentra el principio que pasaré a profundizar a continuación, y me refiero específicamente a la extensión universitaria.

Para dar una primera precisión de lo que se entiende por extensión universitaria, podría citar la definición plasmada en la Resolución № 357/2014 de la Universidad Nacional de La Pampa, que en el Artículo $1^{\circ}$ del Anexo I indica que la extensión

“..., Se define como la puesta en práctica en la comunidad, a la que pertenece, de los saberes adquiridos en la docencia y la investigación, lo cual permite vincularlos con la realidad del territorio en el que se construyen y realizar nuevos aportes e hipótesis de trabajo. Esta construcción es colectiva y dialógica, y en ella interactúan los conocimientos científicos con los saberes y conocimientos de la comunidad."

La incorporación de la extensión en el ámbito universitario fue posible, porque los estudiantes impulsores de la Reforma se adelantaron a su época, fueron visionarios y comprendieron, que la Universidad no debía ser un ámbito exclusivo para las elites de la sociedad, que se encargara de formar futuros profesionales para conservar la división clasista que el mundo desde los orígenes de los tiempos parecía haber convalidado. Contrapuestos a esta idea, aquellos estudiantes entendieron a la Universidad como una forma de escape a la opresión social, y por lo tanto, como la posibilidad que sus antecesores no habían tenido para poder lograr un mejor status en una sociedad tan injusta y desigual como la de aquel momento.

En este sentido, afirma Carlos Tünnermann que

“... el Movimiento agregó, al tríptico misional clásico de la Universidad, un nuevo y prometedor cometido, capaz de vincularla más estrechamente con la sociedad y sus problemas, de volcarla hacia su pueblo, haciéndolo partícipe de su mensaje, transformándose en su conciencia cívica y social."

Pero para comprender acabadamente el alcance de la extensión universitaria, es necesario analizarla a partir de una doble perspectiva, desde la contribución de la sociedad a la Universidad y desde la contribución de la Universidad a la sociedad. Desde la contribución de la sociedad, porque el proceso de conocimiento de los estudiantes no puede abstraerse de la historia y la cultura. El aprendizaje es una construcción intersubjetiva que se desarrolla a partir de la comunicación de los actores intervinientes (en este caso los estudiantes y la sociedad), por eso deben tenerse en cuenta no sólo los sujetos sino también los ámbitos en que se desarrolla. Desde la contribución de la sociedad, porque los programas de extensión universitaria, tienen como objetivo principal la puesta en marcha de procesos de intervención en el campo social "entendido éste como un conjunto de acciones planificadas e interrelacionadas que se ponen en movimiento para abordar/resolver problemas sociales determinados." ${ }^{2}$

\footnotetext{
${ }^{2}$ Integración, docencia y extensión.
} 
Como podemos ver, la extensión universitaria debe concebirse como un proceso de retroalimentación o feed back, el cual permite que las partes intervinientes emitan (in put) y reciban (out put) aportes positivos para la construcción de lo que se conoce como "Universidad de puertas abiertas".

Debemos tener presente que "Las relaciones intersubjetivas que se dan en la extensión universitaria, en tanto acción dialógica, posibilitan construir prácticas democráticas de comunicación y formación entre los sujetos y las instituciones." ${ }^{3}$ Y por ello entender que, si pretendemos que la educación se desenvuelva acorde con parámetros de democracia y justicia, debemos revalorizar la función de la extensión universitaria en todas las Casas de Estudio del país.

Con ese objetivo, la mayoría de las Casas de Estudio a lo largo y ancho del país, han ido plasmando la extensión universitaria en sus Estatutos Estudiantiles, convirtiéndola en una obligación inescindible de las Universidades. Un ejemplo de ello lo constituye la Universidad Nacional de La Pampa, que siendo fundada el 4 de Septiembre de 1958, incorporó en su Estatuto en la sección "Bases y Objetivos" el siguiente precepto: "La Universidad, además de su tarea específica de centro de estudios y de enseñanza superior procura difundir los beneficios de su acción cultural y social directa, mediante la extensión universitaria."

Si bien, la incorporación de la extensión en los Estatutos, implica un gran paso, no sólo es necesario establecerla como mandato programático en los Estatutos Universitarios, sino que hay que poner en marcha herramientas y mecanismos de acción que logren plasmar la importancia de conectar a la sociedad con la educación, ya que ninguna puede subsistir sin la otra.

Una de las formas de hacerlo, es llevando a cabo Proyectos concernientes a poner en práctica de manera efectiva actividades extensionistas. En el caso de la Universidad Nacional de La Pampa, específicamente en la Facultad de Ciencias Económicas y Jurídicas, fue en el año 2011 cuando se inauguró un nuevo ciclo extensionista, poniendo en funcionamiento los "Consultorios Jurídicos Gratuitos", regulados cuatro años después mediante la Resolución N070/15. Según el Reglamento contenido en el Anexo I de la Resolución mencionada, "..., En estos consultorios se realizará la orientación jurídica a los grupos más vulnerables de la población con dificultades en acceder al conocimiento de los derechos básicos." Es decir que, si bien no se ofrece patrocinio letrado, se orienta a las personas que se encuentren en estado de vulnerabilidad acerca de cuáles son sus alternativas de acción en el ámbito jurídico. Asimismo, los consultorios no se limitan a hacer meras interpretaciones legales, sino también a ofrecer cierta contención en los límites de lo posible para aquellas personas que tienen un acceso restringido a la justicia.

Actualmente los Consultorios Jurídicos Gratuitos en funcionamiento en la ciudad de Santa Rosa se encuentran en: Barrio Escondido, Barrio Aeropuerto, Barrio Villa Germinal, Barrio Reconversión, y Barrio Villa Santillán. Por su parte, en la localidad de General Pico, el Consultorio Jurídico Gratuito se ubica en el Barrio Frank Allan. Finalmente en la localidad de Toay, el Consultorio Jurídico Gratuito funciona en la Secretaría de Acción Social del Municipio. Por lo que, si bien hay muchos lugares en La Pampa que aún no tienen con

\footnotetext{
${ }^{3}$ Integración, docencia y extensión.
} 
consultorios jurídicos gratuitos, podría decirse que la mayoría de los principales centros poblacionales de la Provincia cuentan con este programa.

Este tipo de proyectos, que son claramente fundacionales en la labor extensionista de la UNLPam, implican un gran primer paso para la transformación de las Casas de Estudios comprometidas con la realidad social en la que se desenvuelven. No obstante, dicha tarea transformadora es inagotable, y más aún, cuando se desarrolla en un ámbito donde subsisten viejos resabios del modelo educativo que imperó en la época de la Reforma Universitaria.

Para ello, es necesario encarnar lo que en términos gramscianos se conoce como "lucha cultural", que según Gramsci implica entre otras cosas que "hay que dejar de concebir la cultura como saber enciclopédico, en el cual el hombre no se contempla más bajo la forma de recipiente que hay que llenar con datos empíricos e inconexos".

Los estudiantes y la sociedad toda, tienen que tomar consciencia de la realidad social, política, económica y cultural en la que viven, para entender el valor histórico que tienen, sus derechos y deberes, en pos de la construcción de una sociedad más justa.

${ }^{3}$ Gramsci, A.: "Socialismo y Cultura", en II Grido di Popolo, 1916, artículo reproducido en Ontología, pp. 14-17, Sacristán, de Siglo XXI, Madrid, España. 